\title{
História
}

\section{Entrevista com Elcie Aparecida Fortes Salgado MasinI}

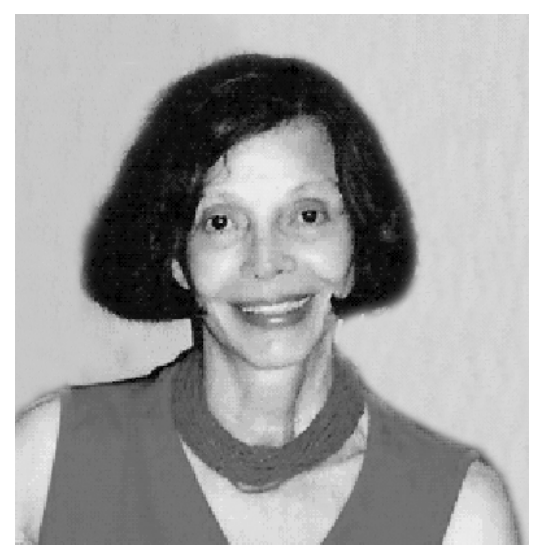

Entrevistadora:Lucicleide Maria de CANTALICE

\section{Entrevista com a professora Elcie Aparecida Fortes Salgado Masini para a ABRAPEE}

Prof $^{a}$ Elcie Aparecida Fortes Salzano Masini é livre docente em Educação Especial pela Universidade de São Paulo. Atualmente, compõe a equipe do Programa de Mestrado em Distúrbios do Desenvolvimento da Universidade Presbiteriana Mackenzie, onde ministra as disciplinas "Metodologia de pesquisa em Ciências Humanas" e "Deficiências Sensoriais - percepção e cognição"; coordena os cursos lato sensu deste Programa "Psicopedagogia" (criado em 1998) e "Formação de Educadores de Pessoas com Deficiências sensoriais e múltiplas” (criado em 2000 - curso este realizado em convênio com o "Programa Hilton Perkins para a educação do surdocego e da pessoa com múltipla deficiente sensorial”). Iniciou a sua prática na Pedagogia como orientadora educacional num colégio vocacional, sendo convidada posteriormente a lecionar no curso de Psicologia. Aprofundou seus estudos nessa área ampliando - os com trabalhos na Psicologia da Comunicação, na Avaliação do Deficiente Visual e Orientação Educacional do Deficiente Visual. A partir de 1983 seu trabalho direcionou-se a formar professoras especializadas no ensino do deficiente visual. Aposentouse em 1994 na USP, porém, continuou a participar ativamente do Laboratório Interdisciplinar de Estudos sobre as Deficiências (LIDE), do qual é sócia fundadora, locado no Instituto de Psicologia da USP. Sua atuação em Psicologia Educacional concentra - se no ato de aprender e na área da excepcionalidade: e continua orientando doutorados e mestrados na USP e mestrados no Mackenzie; desenvolvendo pesquisas junto ao $\mathrm{CNPq}$ e Mackpesquisa, e publicações em livros e artigos, merecendo destaque pelas suas valiosas contribuições.

Lucicleide: Prof ${ }^{\text {a }}$ Elcie, por que escolheu a Pedagogia por profissão e direcionou seu trabalho para a área de psicologia escolar educacional?

Prof ${ }^{a}$ Elcie: Minha escolha pela Pedagogia, creio, irrompeu de motivos profundos que emergiram de diversas vivências: de minha experiência no início da escolarização, que ficou emersa em tons sombrios, conservando em mistério passagens da própria vida e 
em esquecimento processos próprios importantes, como por exemplo o de aprender a ler; da propulsão de destrinçar o que transforma, na escola, uma criança plena de excitação e curiosidade pelo que a rodeia em alguém passivo e entediado; da crença de que a escola poderia ser um ambiente em que o aluno se sentisse bem e as condições favorecessem seu desenvolvimento, ampliasse suas potencialidades e respeitasse sua maneira própria de organizar, elaborar e realizar.

A Pedagogia encontra seus fundamentos na Sociologia, História, Biologia, Psicologia, Filosofia. Embora o conhecimento dessas áreas fosse indispensável e, no meu Curso os professores das disciplinas fossem autoridades reconhecidas, cada uma das áreas permanecia em um domínio isolado. Naquela época as três áreas de atuação do pedagogo eram: a da administração escolar, que se voltava a atividades ligadas à direção cuidando da estrutura organização e funcionamento da instituição; a área do ensino que se voltava a atividades ligadas à coordenação pedagógica, didática e práticas dos professores; a área da orientação educacional focalizando o aluno, (por meio de atividades com grupos de estudantes, de professores, de pais) para acompanhamento do seu processo de participação, relacionamentos e aprendizagem. Optei pela orientação educacional.

Comecei a atuar como orientadora educacional, após uma especialização de dois anos na Faculdade de Educação da USP. Na função de orientadora educacional tive o privilégio de compor a equipe do Colégio Vocacional "Oswaldo Aranha"- colégio experimental estadual - sob a coordenação geral da educadora Maria Nilde Mascellani. Esse colégio propiciava condições educacionais realizando um trabalho interdisciplinar que surgia de planejamento das áreas e discussões da equipe de professores para ministrarem os conteúdos levando os alunos a refletirem sobre o contexto social e problemática da comunidade em que estavam inseridos; respeitava - se a individualidade, ampliando as potencialidades do aluno organizar, elaborar e atuar coletivamente. Tive aí oportunidade de compartilhar da formação de jovens, hoje cidadãos de meia idade, que prestam serviços significativos em diferentes áreas como Jornalismo, Medicina, Educação e muitas outras. São exemplos vivos de que a sociedade pode contar com homens de responsabilidade, mentalidade independente e atuantes, quando são oferecidas condições educacionais, que consideram os alunos em suas individualidades e as características do contexto social e da sua época. Aprendi muito nesse trabalho sobre condições requeridas para o desenvolvimento e psicologia educacional.

Devido a essa minha atuação no Colégio Vocacional, fui convidada a lecionar no Curso de Psicologia da antiga Faculdade Sedes Sapientiae, na formação do psicólogo escolar; na Faculdade de Psicologia São Marcos, hoje Universidade São Marcos; e no Curso de Psicologia da PUCSP. A partir daí passei a aprofundar meus estudos na área de Psicologia.

\section{Lucicleide: Conte-nos um pouco de sua trajetória profissional.}

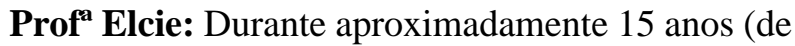
1972 a 1986) estive participando da formação de psicólogos. A preocupação central era de que estes tivessem uma visão crítica sobre o significado de sua atuação na escola, no uso de recursos, técnicas e instrumento frente ao papel da escola pública no contexto social, dos anos 70 a meados de 80 . Organizei dados dessa experiência de trabalho no livro que publiquei em 1978 “Ação da Psicologia na Escola”, prefaciado pelo Dr. Joel Martins, e re editado em 1982.

As questões que os alunos traziam em supervisão dos estágios realizados nas escolas mostraram - me a necessidade de aprofundar meus estudos, o que me levou ao Mestrado em Psicologia Educacional e ao Doutorado em Psicologia (área de concentração Educação). Na tentativa de superar o despreparo referente aos processos de aprendizagem, que encontrei entre professores da escola pública, como também entre os psicólogos formados e os que lecionavam na Universidade, optei por este tema em minha Dissertação. Fiz a sistematização da Teoria da Aprendizagem Significativa (TAS) de Ausubel e sua aplicação em sala de aula numa pesquisa em escola pública estadual de São Paulo. (publicada no livro "Aprendizagem Significativa - a teoria de David Ausubel" em co - autoria com Marco Antonio Moreira, em 1982). As conclusões dessa investigação, bem como sua utilização por professoras nas escolas, assinalaram dúvidas quanto a segurança de atingir com a sistematização e aplicação da TAS o que Ausubel considerava o fator isolado mais importante para a aprendizagem "aquilo que o aprendiz já sabe". Elucidou - se na prática, que o "saber" em Ausubel ficava restrito ao aspecto 
intelectual (denotativo) e o "saber" que o aluno dispõe vem de sua experiência, composta de sentimentos, emoções, valores, hábitos (conotativo/existencial). Essa constatação levou - me no Doutorado a buscar a forma requerida para o "aproximar - se" do aluno e de seu "saber" (conotativo/existencial), fundamentada na Daseinsanalyse - interpretação de Boss e Spanoudis sobre a Análise Existencial de Heidegger.

Do entrelaçamento das experiências de investigação fundamentadas na TAS e do "aproximar - se" daseinsanalítico surgiu o conceito de "Äprendizagem Totalizante”, publicado em livro com o mesmo título, em 1999.

Em 1980, fui convidada pela Dra Elza Dias Pacheco para ministrar Psicologia da Comunicação, na Escola de Comunicações e Artes (ECA), na USP. Foi uma experiência desafiadora participar da formação de futuros comunicólogos ( jornalistas/ cineastas/ programadores de atividade de rádio e $\mathrm{TV} /$ publicitários ) e das questões éticas a serem enfrentadas e discutidas conforme segue. Como discutir teorias de personalidade e as necessidades básicas que movem o homem com aqueles alunos que teriam nas mãos os recursos para manipular o público a partir dessas necessidades? Como examinar os ideais da cultura do século XX, de Morin e a utilização desses ideais nos meios de divulgação, introduzindo outro referencial de valores além dos da habilidade técnica e do sucesso? Ministrar essa disciplina ampliou minha visão sobre questões psicológicas imbricadas na cultura de massas: a relatividade da autonomia das escolhas, os recursos de persuasão e manipulação, a cooperação e a competição com a educação formal e o processo de aprendizagem dos alunos. Foi uma experiência bastante rica, que deixei em 1983, quando fui convidada a assumir aulas nas disciplinas "Avaliação do deficiente visual" e "Orientação educacional do deficiente visual", na Faculdade de Educação da USP

Minha experiência com deficientes visuaisinício de minha carreira profissional - estava muito distante. Parecia - me, por um lado, temerário reassumir encargos ligados à Educação Especial, por outro lado desafiante saber no que minha experiência e conhecimentos, com alunos sem deficiência visual, poderiam contribuir para a educação e o desenvolvimento de pessoas com deficiência visual. A linha central da programação das disciplinas sob minha responsabilidade enfatizava: ter clareza sobre as especificidades do desenvolvimento da pessoa com deficiência visual, sobre os recursos para avaliá-lo para definir a orientação educacional apropriada. A consulta à bibliográfica especializada nacional e estrangeira, bem como a consulta a especialistas em deficiência visual para compor meu planejamento das disciplinas causou - me enorme impacto: o referencial de desenvolvimento e de aprendizagem utilizados em pesquisas e atendimento da pessoa com deficiência visual eram os utilizados com pessoas videntes (sem deficiência visual). Assim a pessoa com deficiência visual permanecia oculta, ao ser estudada por um referencial comparativo. Daí nasceu a pergunta diretriz de minha pesquisa de livre docência, inspirada na "Fenomenologia da Percepção" de Merleau - Ponty: como saber sobre a percepção do deficiente visual, sobre seus processos de organização e elaboração de dados, para um orientação educacional apropriada? A partir de meu concurso de Livre Docência na USP, em 1990, estive formando professoras especializadas no ensino do deficiente visual enfatizando a importância de partir do referencial perceptual do aluno deficiente visual para que ele possa compreender e elaborar dados do mundo que o cerca e das informações recebidas. Aposentei - me em 1994.

Continuei, porém, a participar ativamente do Laboratório Interdisciplinar de Estudos sobre as Deficiências (LIDE), do qual sou sócia fundadora, locado no Instituto de Psicologia da USP. Entre atividades de eventos, debates de pesquisas, projeção e discussão sobre filmes, publicação de livro junto à equipe do LIDE realizei, também, várias investigações junto ao $\mathrm{CNP}$, sobre aprendizagem e condições para a inclusão escolar do aluno com deficiência visual.

Em 1998, a convite da Dra Maria Eloisa Famá D“Antino, passei a compor a equipe do Programa de Mestrado em Distúrbios do Desenvolvimento, da Universidade Presbiteriana Mackenzie, onde ministro as disciplinas "Metodologia de pesquisa em Ciências Humanas" e "Deficiências Sensoriais - percepção e cognição"; coordeno os cursos lato sensu deste Programa "Psicopedagogia" (instalado em 1998) e "Formação de Educadores de Pessoas com Deficiências sensoriais e múltiplas” (instalado em 2000 curso este realizado em convênio com o "Programa Hilton Perkins para a educação do surdocego”) Neste programa venho realizando pesquisas, financiadas pelo CNPq e pelo Fundo de Pesquisa Mackenzie, sobre aprendizagem de pessoas com deficiências sensoriais e 
sem deficiências sensoriais. Sobre as área de atuação e pesquisa nesta Universidade de 1998 até o momento temos realizado eventos e publicações (seis livros e organização de duas revistas da pós - graduação).

\section{Lucicleide: Se pudesse refazer a trajetória de} sua vida profissional, escolheria outra área da Psicologia para atuar? Por quê?

Prof ${ }^{\mathbf{a}}$ Elcie: Não mudaria minha área. A Psicologia Educacional tem respondido ao meu interesse em compreender o ser humano - como percebe, sente, organiza, elabora e age. Há ainda muito a caminhar e aprofundar, porém sem mudar os velhos rumos.

Lucicleide: $O$ que considera mais marcante no estágio atual da Psicologia Escolar no Brasil?

Prof ${ }^{\mathbf{a}}$ Elcie: Não tenho acompanhado o que está sendo realizado em psicologia nas escolas, portanto não me sinto com autoridade para opinar. Tenho tido, apenas, oportunidade de emitir parecer a respeito de projetos de pesquisas encaminhados pelo CNPq. Há projetos de pesquisa bem estruturados, com metodologia coerente com a fundamentação, apresentando continuidade na investigação. Porém, não tenho dados, nem condições para responder à sua pergunta e à questão que me parece prioritária para a realidade educacional brasileira: a Psicologia Educacional tem contribuído para o desenvolvimento e aprendizagem dos alunos das escolas públicas?

\section{Lucicleide: Qual a contribuição que a Psicologia} Escolar pode dar à sociedade brasileira?

Prof ${ }^{a}$ Elcie: Sem desconsiderar a necessidade de mudanças básicas na educação, envolvendo a estrutura social- política - econômica, para beneficiar um número maior de crianças e jovens, as questões sobre o desenvolvimento e aprendizagem na escola é um dos maiores desafios que o psicólogo pode enfrentar. Realizar um trabalho no contexto escolar, junto à equipe de técnicos e professores, assessorando - a, e lidando com as relações conflitantes nessa instituição para a realização de um trabalho compartilhado da equipe técnica e docente e dos discentes não é tarefa fácil. Creio, porém que a contribuição da psicologia escolar só poderá ser avaliada a partir de dados de registros longitudinais de atividades desenvolvidas no contexto da escola. Parece- me que a psicologia escolar brasileira terá sua identidade se for desenvolvida na instituição escolar pública. Assim registrará sua própria história e as diretrizes para o seu futuro. 